\title{
A importância da visita pré-operatória de enfermagem no pós-operatório de cirurgia cardíaca
}

\author{
Alessandra Gomes da Conceição*, Érika da Costa Ribeiro*, Priscila Novaes*, Rízia Duarte dos Santos*, \\ Edvane Mauricio da Silva**, Diego Pereira Rodrigues ${ }^{* * *}$
}

*Enfermeiras, graduadas no Centro Universitário Plinio Leite (UNIPLI), Niterói/RJ, ${ }^{*}$ Enfermeira do Laboratório Sérgio Franco Medicina Diagnóstica, Niterói-RJI, Especialização em Enfermagem do Trabalho pela Universidade Gama Filho (UGF), ${ }^{* *}$ Enfermeiro Supervisor de Campo do Centro Universitário Plínio Leite (UNIPLI), Niterói-RJ/, Especialização em Enfermagem do Trabalho pela Universidade Gama Filho (UGF)

\section{Resumo}

O momento da cirurgia cardíaca em geral é delicado e exige da equipe de saúde uma boa preparação deste cliente. Nesta ótica o enfermeiro assume papel de vital importância, utilizando-se da visita pré-operatória para contribuir na dinâmica descrita. Assim, o objetivo deste estudo foi analisar a influência da visita pré-operatória de enfermagem no pós-operatório imediato do paciente submetido à cirurgia cardíaca. Trata-se de um estudo descritivo e exploratório, com abordagem qualitativa que utilizou como método a revisão bibliográfica e obteve oito artigos como bibliografia potencial. Observou-se que a visita pré-operatória realizada pelo enfermeiro de forma planejada e humanizada pode diminuir os riscos na sala de operaçáo e ao mesmo tempo tranquilizar o paciente tornando a assistência mais eficaz e direcionada para o atendimento das necessidades do cliente. Então, concluímos que o enfermeiro possui o conhecimento científico adequado sobre as fases do processo, devendo preconizar uma assistência mais humanizada e integral, favorecendo o enfretamento do cliente nas suas questóes pertinentes do processo cirúrgico.

Palavras-chave: enfermagem cirúrgica, assistência de enfermagem, enfermagem pré-operatória, cirurgia cardíaca.

\section{Abstract}

\section{The importance of nursing preoperative visiting in the postoperative cardiac surgical}

The timing of the cardiac surgery in general is a delicate procedure and requires competence of health team to prepare this patient to the intervention. In this perspective the nurse assumes the role of vital importance, using the preoperative visiting to contribute to the dynamics described. The objective of the study was to analyze the influence of nursing preoperative visiting in the postoperative patient who is undergoing cardiac surgery. It is a descriptive and exploratory study with qualitative approach which used a literature review and selected eight articles as potential references. It was observed that the preoperative visiting conducted by nurses in a planned and humanized way can reduce the risks in the operating room and reassure the patient, 
thus care delivery will become more effective and meet the needs of the client. We conclude that the nurse has adequate scientific knowledge about the process stages, and should preconize a more humane and comprehensive care, encouraging the patient to face relevant questions concerning surgical process.

Key-words: surgical nursing, nursing care, nursing pre-operative cardiac surgery.

\section{Resumen}

\section{La importancia de la visita preoperatoria de enfermería en el postoperatorio de cirugía cardiaca}

El momento de la cirugía cardíaca en general es delicado y requiere competencia del equipo de salud para preparar el paciente. Bajo esta óptica, el enfermero desempeña un papel de vital importancia, utilizando la visita preoperatoria para contribuir en la dinámica descrita. El objetivo de este estudio es analizar la influencia de la visita preoperatoria de enfermería en el postoperatorio de paciente que se somete a cirugía cardíaca. Es un estudio descriptivo y exploratorio con enfoque cualitativo que utilizó como método la revisión de literatura. Después de la búsqueda en distintas fuentes de información, se encontraron ocho estudios como bibliografía potencial. Se observó que la visita preoperatoria realizada por el personal de enfermería en forma planificada y humanizada puede reducir los riesgos en los quirófanos y al mismo tiempo tranquilizar el paciente, haciendo la atención más eficaz y orientada a satisfacer las necesidades del paciente. Por lo tanto, se concluye que el enfermero tenga el conocimiento científico adecuado acerca de las fases del proceso, y preconizar una atención más humana e integral favoreciendo el enfrentamiento del paciente en sus cuestiones relevantes al proceso quirúrgico.

Palabras-clave: enfermería quirúrgica, cuidados de enfermería, enfermería pre-operatorio de cirugía cardiaca.

\section{Introdução}

A cirurgia é um procedimento em que ocorrem inúmeras e variadas complicaçôes, principalmente no período pós-operatório imediato, podendo trazer implicaçôes importantes à saúde e ao bem-estar do paciente. Para que o momento perioperatório transcorra da melhor maneira possível, é necessária uma assistência de saúde que atenda a todas as necessidades do cliente.

O pós-operatório imediato compreende o momento mais crítico para o paciente, e, desta forma, exige maior vigilância por parte dos profissionais de enfermagem, pois ocorre um maior número de complicaçôes, necessitando, assim, dos cuidados de enfermagem [1].

No período pós-operatório, o paciente fica vulnerável a diversas complicaçóes, especialmente as de origem respiratória, circulatório e gastrointestinal. Assim sendo, a incidência de complicaçóes imediatamente após a cirurgia está geralmente associada às condiçôes clínicas pré-operatórias, à extensão e ao tipo de cirurgia, às intercorrências cirúrgicas ou anestésicas e à eficácia das medidas terapêuticas adotadas [2].

Diante desse contexto, faz-se necessária a utilização dos protocolos cirúrgicos e das rotinas de enfermagem, oferecendo uma assistência pré-operatória integral e humanizada ao paciente, ou seja, a consulta pré-operatória de enfermagem. É de praxe que a enfermagem participe da fase pré-operatória, seja na administração de medicamentos, seja no preparo do organismo (mente, corpo e espírito) e da área do corpo em que será realizada cirurgia, o que implica em pelo menos uma visita do profissional de enfermagem ao paciente [3].

A fase pré-operatória é o período que tem início a partir da decisão para intervenção cirúrgica até o momento em que o paciente é transferido para a mesa na sala de operação [3].

Os dados ou informaçóes levantados na visita pré-operatória, além de oferecerem subsídios para a identificação de problemas ou alteraçôes relacionadas aos aspectos bio-psico-sócio-espirituais do paciente, podem influenciar de maneira significativa tanto no procedimento anestésico-cirúrgico como na reabilitação do paciente. Além disso, proporcionam que a realização do planejamento de assistência contínua de enfermagem seja uma oportunidade para o enfermeiro dialogar com o paciente, orientando, esclarecendo dúvidas e, principalmente, estabelecendo um vínculo de confiança com o paciente cirúrgico [2].

Nesta fase, a educação em saúde é um aspecto importante para sua experiência cirúrgica. $\mathrm{O}$ 
ensino pré-operatório relativo ao comportamento pós-operatório esperado de um paciente fornecido em formato estruturado e sistemático conforme os princípios de ensino e aprendizagem apresentam influência positiva sobre a recuperação do paciente [4].

Portanto, tomamos como problema norteador da pesquisa a seguinte questáo: Qual a influência da visita pré-operatória de enfermagem no pós-operatório imediato do paciente que é submetido à cirurgia cardíaca?

Tendo em vista a questáo em destaque, o objetivo do estudo consiste em analisar a influência da visita pré-operatória de enfermagem no pós-operatório imediato do paciente que é submetido à cirurgia cardíaca, por ser uma cirurgia complexa e que gera mais medos e incertezas para a maioria da população.

Salientamos que a justificativa pelo estudo é pelo fato de apresentar poucos estudos acerca da temática. Por isso, buscamos que o enfermeiro, nesse contexto, junto ao paciente cirúrgico tenha a oportunidade de implementar uma assistência no período pré-operatório, contribuindo na qualidade prestada de forma integral e humanizada que certamente influencia no sucesso do tratamento cirúrgico.

A atuação do enfermeiro é de extrema importância no período que antecede a cirurgia, pois avalia as necessidades de uma assistência integral individualizada, favorecendo a qualidade em saúde, por isso, faz-se necessária a valorizaçáo do trabalho prestado por este profissional.

Assim, relevamos na pesquisa as suas possibilidades de contribuir para a nossa formação, entendendo que, a partir da mesma, tenhamos a oportunidade de adquirir conhecimento em relação à importância da assistência de forma humanizada do enfermeiro ao paciente em preparo para cirurgia, usando como rotina fundamental: a visita pré-operatória, com vistas a reduzir complicaçóes no pós-operatório imediato, assegurando eticamente os direitos do paciente, possibilitando uma assistência individualizada e favorecendo o seu retorno rápido ao meio social.

Da mesma forma, esperamos que os resultados do estudo possam contribuir para que os trabalhadores de enfermagem reflitam sobre suas práxis, a fim de construir laços de entendimento que conduzam a uma concepçáo cada vez mais sedimentada sobre um cuidado sem fragmentá-lo, além de poder garantir um atendimento humanizado e qualificado ao paciente no perioperatório. Enfim, contribuir para a pesquisa, intensificando as relaçóes no cuidar/ cuidado, no processo saúde-doença do paciente.

\section{Material e métodos}

A pesquisa é requerida quando não se dispôe de informação suficiente para responder ao problema, ou então quando a informação disponível se encontra em tal estado de desordem que náo possa ser adequadamente relacionada ao problema [5].

Trata-se de um estudo descritivo e exploratório, pois se refere a abordagens de pesquisas que geralmente irão proporcionar maior familiaridade com o problema pesquisado, com vistas a torná-lo mais explícito ou a constituir hipóteses [5]. Pode-se dizer que estas pesquisas têm como objetivo principal o aprimoramento de ideias ou a descoberta de intuiçóes expondo as características de determinada população ou de determinado fenômeno, estabelecendo as correlações entre variáveis e definindo sua natureza [6]. Visando atender aos objetivos especificados neste estudo, utilizou-se o método de revisão de literatura, que tem como finalidade sintetizar resultados obtidos em pesquisas relativos ao tema ou a uma questão específica, de forma sistemática e ordenada com o intuito de contribuir para o conhecimento dessa temática [6].

O levantamento bibliográfico foi realizado em março de 2010, com base na Biblioteca Virtual de Saúde (BVS), utilizando as bases de dados Lilacs (Literatura Latino-Americana e do Caribe em Ciências da Saúde) SciELO (Scientific Eletronic Library Online), BDENF (Base de Dados de Enfermagem).

Para a coleta de dados utilizamos os seguintes descritores: Enfermagem cirúrgica; Assistência de enfermagem; Enfermagem pré-operatória; Cirurgia cardíaca. Outras fontes de informaçóes como bibliotecas também foram utilizadas para fomento de informaçóes relativas à confecção deste estudo; assim como toda produçáo temporal entre o período de 2000 a 2009 . Ressalta-se que, inicialmente, pesquisamos cada descritor individualmente. Após a coleta de dados inicial, percebemos excesso de trabalhos sobre a temática, o que náo poderia atender ao objetivo da pesquisa. Desta forma, optamos por realizar uma busca com os descritores associados em dupla e em trio, para obtermos assim um melhor resultado, conforme o Quadro I e II. 
Quadro I - Distribuição quantitativa das referencias bibliográficas encontradas nas bases de dados segundo os descritores associados.

\begin{tabular}{|l|l|l|l|l|}
\hline \multirow{2}{*}{ Descritores } & \multicolumn{3}{c|}{ Base de dados } \\
\cline { 2 - 5 } & Lilacs & Bdenf & Scielo & Total \\
\hline $\begin{array}{l}\text { Enfermagem pré-ope- } \\
\text { ratória X Assistência de } \\
\text { enfermagem }\end{array}$ & 30 & 29 & 00 & 59 \\
\hline $\begin{array}{l}\text { Enfermagem pré-ope- } \\
\text { ratória X Enfermagem } \\
\text { cirúrgica }\end{array}$ & 13 & 12 & 02 & 27 \\
\hline $\begin{array}{l}\text { Enfermagem pré- } \\
\text {-operatória X Cirurgia } \\
\text { cardíaca }\end{array}$ & 04 & 03 & 00 & 07 \\
\hline $\begin{array}{l}\text { Assistência de enfer- } \\
\text { magem X Enfermagem } \\
\text { cirúrgica }\end{array}$ & 44 & 45 & 00 & 89 \\
\hline $\begin{array}{l}\text { Assistência de enfer- } \\
\text { magem X Cirurgia } \\
\text { cardíaca }\end{array}$ & 20 & 15 & 00 & 35 \\
\hline $\begin{array}{l}\text { Enfermagem cirúrgica } \\
\text { X Cirurgia cardíaca }\end{array}$ & 00 & 00 & 00 & 00 \\
\hline TOTAL & 111 & 104 & 02 & 217 \\
\hline
\end{tabular}

A associação dos três termos de forma conjunta permitiu aprofundamento quanto à questão de relacionar os descritores ao objeto de estudo e a problemática a qual se pretende desvendar. Constata-se o observado, através do Quadro II.

Quadro II - Distribuição quantitativa das referências bibliográficas encontradas nas bases de dados segundo os descritores associados - Bibliografia potencial.

\begin{tabular}{|l|l|l|l|l|}
\hline \multirow{2}{*}{ Descritores } & \multicolumn{3}{c|}{ Base de dados } \\
\cline { 2 - 5 } & Lilacs & BDENF & Scielo & Total \\
\hline $\begin{array}{l}\text { Enfermagem pré-ope- } \\
\text { ratória X Assistência } \\
\text { de enfermagem X } \\
\text { Enfermagem cirúrgica }\end{array}$ & 08 & 01 & 01 & 10 \\
\hline $\begin{array}{l}\text { Enfermagem } \\
\text { pré-operatória X } \\
\text { Assistência de enfer- } \\
\text { magem X Cirurgia } \\
\text { cardíaca }\end{array}$ & 02 & 03 & 04 & 09 \\
\hline $\begin{array}{l}\text { Assistência de en- } \\
\text { fermagem X Enfer- } \\
\text { magem cirúrgica X } \\
\text { Cirurgia cardíaca }\end{array}$ & 00 & 01 & 04 & 05 \\
\hline TOTAL & 10 & 04 & 09 & 24 \\
\hline
\end{tabular}

Após o levantamento bibliográfico, realizou- -se a pré-leitura do material encontrado. Com essa leitura, pode-se obter uma visão global do material, considerando de interesse ou não para pesquisa. Foram descartados os trabalhos que não condiziam com o nosso objetivo e que se repetiam nos acervos consultados. Em seguida, efetuou-se a leitura seletiva, que permitiu determinar qual o material bibliográfico que realmente era de interesse para esta pesquisa.

Destaca-se que dentre os artigos selecionados como potenciais houve o descarte de 16 artigos por não se enquadrar no objeto de pesquisa. Assim chegamos a um total de oito artigos potenciais para análise de dados.

Com os artigos em mãos, realizou-se leitura crítica e interpretativa e fez-se a análise temática de conteúdo. Assim, emergiram as seguintes categorias: o processo cirúrgico; cirurgias cardíacas; fases de cirurgias; assistência de enfermagem no pré-operatório; influência da visita de enfermagem no pós-operatório imediato.

\section{Resultados e Discussão}

Para melhor compreensão, os artigos incluídos no estudo estão apresentados no Quadro III, os quais foram analisados e organizados nas categorias apresentadas a seguir.

Quadro III - Bibliografia analisada na construção da pesquisa.

\begin{tabular}{|l|l|l|l|}
\hline Autores & Ano & Título & $\begin{array}{l}\text { Base de } \\
\text { dados } \\
\text { tipo/local }\end{array}$ \\
\hline $\begin{array}{l}\text { Fonseca e } \\
\text { Paniche [7] }\end{array}$ & 2009 & $\begin{array}{l}\text { Enfermagem em } \\
\text { centro cirúrgico: Trin- } \\
\text { ta anos após criação } \\
\text { do sistema de assis- } \\
\text { tência de enferma- } \\
\text { gem perioperatória. }\end{array}$ & $\begin{array}{l}\text { Acta Paul } \\
\text { Enferm } \\
\text { Lilacs }\end{array}$ \\
\hline $\begin{array}{l}\text { Neto, } \\
\text { Teixeira e } \\
\text { Barbosa [8] }\end{array}$ & 2008 & $\begin{array}{l}\text { Elaboração de um } \\
\text { instrumento para o } \\
\text { preparo pré-opera- } \\
\text { tório em cirurgias } \\
\text { cardíacas. }\end{array}$ & $\begin{array}{l}\text { O Muno Paulo } \\
\text { da Saúde } \\
\text { Lilacs }\end{array}$ \\
\hline $\begin{array}{l}\text { Grittem, } \\
\text { Méier e } \\
\text { Gaievicz } \\
\text { [12] }\end{array}$ & 2006 & $\begin{array}{l}\text { Visita pré-operatória } \\
\text { de enfermagem: } \\
\text { Percepções dos } \\
\text { enfermeiros de um } \\
\text { hospital de ensino. }\end{array}$ & $\begin{array}{l}\text { Cogitare } \\
\text { Enferm } \\
\text { Scielo }\end{array}$ \\
\hline
\end{tabular}




\begin{tabular}{|c|c|c|c|}
\hline $\begin{array}{l}\text { Moraes e } \\
\text { Peniche } \\
{[13]}\end{array}$ & 2003 & $\begin{array}{l}\text { Assistência de enfer- } \\
\text { magem no período } \\
\text { de recuperação } \\
\text { anestésica: Revisão } \\
\text { literária. }\end{array}$ & $\begin{array}{l}\text { Rev Esc En- } \\
\text { ferm USP } \\
\text { Lilacs }\end{array}$ \\
\hline $\begin{array}{l}\text { Ferraz, } \\
\text { Ferraz, } \\
\text { Bacelar, Al- } \\
\text { buquerque, } \\
\text { Vasconcelos } \\
\text { e Leão [14] } \\
\end{array}$ & 2001 & $\begin{array}{l}\text { Controle de infecção } \\
\text { em cirurgia geral- } \\
\text {-resultado em um } \\
\text { estudo prospectivo } \\
\text { de } 23 \text { anos e } 42.274 \\
\text { cirurgias. } \\
\end{array}$ & $\begin{array}{l}\text { Rev Col } \\
\text { Bras Cir } \\
\text { Scielo }\end{array}$ \\
\hline Darli [15] & 2005 & $\begin{array}{l}\text { Diagnóstico de } \\
\text { enfermagem de } \\
\text { pacientes em perí- } \\
\text { odo pós-operatório } \\
\text { imediato de cirurgia } \\
\text { colicistectomia lapa- } \\
\text { roscópica. }\end{array}$ & $\begin{array}{l}\text { Universida- } \\
\text { de de SP; } \\
\text { Escola de } \\
\text { enferma- } \\
\text { gem de } \\
\text { Ribeirão } \\
\text { Preto; } \\
\text { dissertação } \\
\text { de mestra- } \\
\text { do }\end{array}$ \\
\hline $\begin{array}{l}\text { Ursi e Ga- } \\
\text { vão [16] }\end{array}$ & 2006 & $\begin{array}{l}\text { Prevenção de lesão } \\
\text { de pele perioperató- } \\
\text { rio: Revisão integrati- } \\
\text { va da literatura. }\end{array}$ & $\begin{array}{l}\text { Rev Latino- } \\
\text { am Enferm } \\
\text { Scielo }\end{array}$ \\
\hline $\begin{array}{l}\text { Picolli e } \\
\text { Galvão [17] }\end{array}$ & 2001 & $\begin{array}{l}\text { Enfermagem perio- } \\
\text { peratória: identifica- } \\
\text { ção do diagnóstico } \\
\text { de enfermagem, } \\
\text { risco para infecção } \\
\text { fundamentada no } \\
\text { modelo conceitual } \\
\text { de Levine. }\end{array}$ & $\begin{array}{l}\text { Rev Latino- } \\
\text { am Enferm } \\
\text { Lilacs }\end{array}$ \\
\hline
\end{tabular}

\section{$\mathrm{O}$ processo cirúrgico}

Nessa fase o enfermeiro tem que estar presente, esclarecendo dúvidas e transmitindo segurança para o paciente, para que o seu comportamento não atrapalhe a reabilitação no pós-operatório. É fundamental que o enfermeiro assuma seu papel nesse contexto, não se ausentando nesse momento crucial para o paciente.

Deve-se entender o momento cirúrgico, em sua dinâmica, uma vez que se relaciona a uma intervenção no estado de saúde do paciente, podendo repercutir de maneira benéfica, ou não, no bem-estar do mesmo, devendo esclarecê-lo em todas as suas dúvidas sobre o que será realizado, permitindo-se que um ambiente e clima de segurança, sejam vivenciados e construídos.
O papel do enfermeiro no centro cirúrgico tem se tornado mais complexo através dos anos, na medida em que necessita integrar as atividades que abrangem a área técnica, administrativa, assistencial, de ensino e pesquisa. $\mathrm{Na}$ integração dessas atividades, nas quais os vários profissionais interagem sob vários aspectos, salienta-se o relacionamento interpessoal, normalmente dificultado em unidade fechada, estressante e dinâmica como o centro cirúrgico [7].

A cirurgia seja eletiva ou de emergência é um evento estressante e complexo para o paciente. Os pacientes com problemas de saúde, cujo tratamento envolve uma intervenção cirúrgica, geralmente se submetem a uma cirurgia, tal procedimento envolve a administraçáo de anestesia local, regional ou geral, aumentando, assim, o grau de ansiedade do paciente, o que provoca alteraçóes emocionais decorrentes do anúncio do diagnóstico cirúrgico. Isso provoca situaçóes desagradáveis no estado bio-psico-sócio-espiritual do paciente, acarretando problemas graves, podendo chegar à suspensão da cirurgia ou até mesmo óbito do paciente [2].

No período pós-operatório o paciente fica vulnerável a diversas complicaçôes, especialmente as de origem respiratória, circulatória, gastrointestinal. Compreendemos que o conhecimento das principais complicaçóes pelo enfermeiro é fundamental, para promover a rápida recuperação do paciente, evitar a infecção hospitalar e reduzir gastos. Destaca-se que a incidência de complicações no pós-operatório imediato está geralmente associada às condiçóes clínicas pré-operatórias, a extensão e ao tipo de cirurgia, às intercorrências cirúrgicas ou anestésicas e a eficácia das medidas terapêuticas adotadas [2].

Na dinamização deste processo, faz-se de suma importância a presença de uma equipe de enfermagem que permita um adequado suporte ao paciente, para que o mesmo antes de todo o processo possa sentir-se seguro para o enfrentamento do momento cirúrgico. Deve-se ter em mente que mesmo no centro cirúrgico o mesmo deve ser visto integralmente e não como um amontoado de partes, a visão do antigo modelo biomédico.

\section{Cirurgias cardíacas}

O coração como um órgão nobre, leva ao paciente cirúrgico medo e desconforto durante o período que antecede a cirurgia, induzindo-o a pensar precocemente na morte. Hoje, com a evoluçấo da 
medicina, o enfermeiro como educador, embasado no conhecimento técnico - científico deve propor conforto a esse paciente.

$\mathrm{O}$ entendimento da anatomia e da fisiologia deste órgão é um dos requisitos básicos para a formação do profissional de enfermagem (tanto de nível médio como superior). Constata-se que o mesmo algumas vezes é subvalorizado nos bancos acadêmicos, o que também carece de revisão importante, pois influencia nossa práxis.

A doença Arterial Coronariana (DAC) é uma das principais causas de morte no Brasil, bem como em outros países, responsável por cerca de $300 \mathrm{mil}$ óbitos anuais. Apresentam-se, também, como uma das principais causas de morte entre a população adulta em idade produtiva, além dos idosos [8]. Dessa forma, a meta na preparação de qualquer paciente para a cirurgia é assegurar um sistema cardiovascular com bom funcionamento para satisfazer as necessidades de oxigenação, hídricas e nutricionais do perioperatório. Como a doença cardiovascular aumenta o risco de complicaçóes, os pacientes com essas condiçôes exigem diligência maior que a usual durante todas as fases do cuidado e tratamento de enfermagem [9].

A equipe encarregada do tratamento cirúrgico dos pacientes portadores de cardiopatias adquiridas ou congênitas é multiprofissional, constando de enfermeiro, fisioterapeuta, médico, nutricionista e assistente social. $\mathrm{O}$ paciente deve ser avaliado no pré-operatório por um ou mais membros da equipe, com o objetivo de produzir a melhor avaliação cardiológica e clínica dos pacientes com indicação de cirurgia cardíaca [8].

O profissional que lida com este tipo de cirurgia deve possuir conhecimento técnico-científico suficiente sobre anatomia e fisiologia cardíaca, sobre as fases do processo cirúrgico que envolve este órgão, bem como toda a tecnologia empregada neste momento, sem deixar de lado o aspecto humano que envolve a assistência neste tipo de procedimento.

A experiência demonstra que nas atividades em que há envolvimento e participação coletiva, como na cirurgia cardíaca, a existência de um conjunto de rotinas e protocolos, à medida que orientam e padronizam os procedimentos, contribui para um cuidado melhor e científico aos pacientes, além de assegurar a continuidade dos tratamentos ministrados [8].

Dentro deste contexto, o enfermeiro, enquanto líder e norteador da equipe de enfermagem, deve esclarecê-la sobre todos os aspectos que envolvem este tipo de cirurgia, bem como os que são de competência de enfermagem, para que fiquem esclarecidos os papéis destes profissionais no processo referido.

Deve-se ter em mente que quando um trabalho em conjunto é realizado o mesmo deve possuir suportes de liderança e orientação. É neste momento que o enfermeiro deve assumir tanto a função de cuidado deste tipo de cliente, como a de liderar sua equipe para a realização de todas as etapas que envolvem este procedimento.

$\mathrm{Na}$ fase pré-operatória, a equipe de enfermagem deve desenvolver um plano de cuidados, a fim de orientar o paciente e seus familiares a respeito das fases do tratamento cirúrgico, bem como prepará-los emocionalmente. Isso deve ser feito de modo a diminuir a ansiedade e o medo, esclarecer eventuais dúvidas e incentivar a participação do paciente $\mathrm{e}$ de seus familiares no processo de recuperação e de autocuidado [10].

A cirurgia cardíaca aberta é geralmente realizada para doença arterial coronariana, disfunção valvular e defeitos cardíacos congênitos. Esse procedimento exige circulação extracorpórea para proporcionar um campo seco, sem sangue durante a cirurgia. Procedimentos mais modernos e menos invasivos de bypass incluem a cirurgia minimamente invasiva para derivação de artéria coronária (MIDCAB) e procedimentos realizados por acesso via portal [11].

Um fator de risco pode ser considerado como qualquer situação, hábito, condição ambiental ou fisiológica capaz de predispor um indivíduo ou grupo a uma doença ou a um estado não saudável. No que tange ao cliente suscetível à cardiopatia, este poderá apresentar tanto fatores de risco mutáveis ou reversíveis (que podem ser mudados, prevenidos e tratados) como imutáveis ou irreversíveis (não podem ser mudados e nem mesmo tratados) [10].

Alguns fatores de risco mutáveis ou reversíveis para doenças cardíacas são tabagismo, colesterol elevado, pressão arterial elevada, vida sedentária, obesidade, diabetes melito, contraceptivos orais e estresse, e alguns fatores de risco imutáveis ou irreversíveis são hereditariedade, idade, sexo e etnia [10].

As complicaçóes após a cirurgia cardíaca podem ser divididas em complicaçóes precoces (cardiovasculares, pulmonares, renais, gastrintestinais e neuropsicológicas) e complicaçóes pós-operatórias tardias [11] 
Nesta ótica o enfermeiro deve utilizar-se de ferramentas semiológicas na identificação de sinais e sintomas, e antes disso, ser observador em relação às condiçóes e sinais que seus clientes possam vir a apresentar durante todo o perioperatório que possa envolver seus clientes.

\section{Fases de cirurgias}

Assim como para as cirurgias cardíacas e os demais procedimentos que envolvam diversos órgãos do nosso organismo, faz-se necessário, tanto para o enfermeiro quanto para toda a equipe de enfermagem, um conhecimento técnico e científico que permita que os mesmos intervenham de maneira benéfica no processo cirúrgico. Nesse sentido, o entendimento correto do pré, do trans e do pós-operatório deste tipo de cliente auxilia na percepção global do processo, o que pode contribuir para uma assistência de enfermagem de melhor qualidade.

A sistematizaçáo da assistência de enfermagem perioperatória (SAEP) é um processo que tem como objetivos promover, manter e recuperar a saúde do cliente e de sua família. A SAEP abrange três fases da experiência cirúrgica: o pré-operatório mediato e imediato, transoperatório e pós-operatório mediato e imediato. Definem-se como pré-operatório mediato o período que se inicia na indicação cirúrgica e internação do paciente até a véspera de sua realização e mais o pré-operatório imediato às 24 horas que antecedem a cirurgia até a admissáo do paciente no centro cirúrgico. $\mathrm{O}$ trans ou intra-operatório é o período compreendido desde a admissão do paciente no centro cirúrgico até a entrada na sala de recuperaçáo pós-anestésica imediato [12].

O período pós-operatório compreende o momento em que o paciente sai da sala de operaçóes até o retorno às suas atividades normais. Sua duração é variável, pois depende do tipo de intervenção cirúrgica e das condiçóes fisiológicas do paciente. O pós-operatório imediato que compreende as primeiras 12 ou 24 horas após o termino da cirurgia. Sua real duraçáo depende do porte ou gravidade da cirurgia e estado em que se encontra o paciente ao seu término. $\mathrm{O}$ período pós-operatório mediato se inicia após as primeiras 24 horas e se desenvolve por um período variável até o dia da alta hospitalar [13].

A distribuição destas fases deve ser bem entendida pelo profissional de saúde, bem como todas as açóes realizadas em todas elas, para que se alcance um resultado positivo do processo cirúrgico cardíaco.

\section{Assistência de enfermagem no pré-operatório}

O enfermeiro neste contexto deve aplicar todo o seu saber técnico-científico para permitir um momento operatório mais seguro possível. $\mathrm{O}$ mesmo através da visita deve verificar pontos-chaves importantes que possam de alguma forma dificultar ou trazer problemas ao momento cirúrgico, buscando a análise de todas as dimensóes de seu cliente (biológicas, psíquicas, sociais e mesmo espirituais).

A necessidade de haver uma comunicação eficiente, clara, e objetiva permite que a assistência iniciada no pré-operatório continue no transoperatório e prossiga no período do pós-operatório, de modo a contribuir para a minimização de complicaçóes.

Devido à possibilidade de complicaçóes no pós-operatório é exigido da enfermagem um sólido conhecimento sobre todos os aspectos do cuidado do paciente cirúrgico. Não mais só o conhecimento sobre a enfermagem pré-operatória e pós-operatória é suficiente, devendo-se ter uma compreensão plena sobre as atividades intraoperatórias. $\mathrm{Na}$ visita pré-operatória de enfermagem do centro-cirúrgico, que consiste em acompanhar o paciente náo só no centro-cirúrgico, mas também durante toda sua estadia no hospital, deve a enfermagem ficar atenta a todas as alteraçóes que poderão surgir e atuar na recuperação plena do paciente [2].

Na visita pré-operatória utilizada como estratégia para qualificar a assistência pode ser oferecida ao paciente a possibilidade do cuidado integral, individualizado, assistência participativa e a possibilidade do paciente expressar sua ansiedade, medo e angústia. Verifica-se que a importância dessa prática não está só relacionada ao paciente, mas também a realização pessoal do profissional [13].

Esta ferramenta empregada de forma correta pelo enfermeiro particulariza as atividades realizadas pelo mesmo, fazendo com que o mesmo possa ser reconhecido em suas açóes e também enquanto membro da equipe multiprofissional.

Como na fase pré-operatória tem sido dada uma importância grande ao asseio corporal e à higiene dos pacientes que seráo submetidos a procedimentos cirúrgicos, os pacientes, ainda no ambulatório devem ser orientados a tomar banho completo e realizar limpezas de áreas críticas do corpo. $\mathrm{Na}$ enfermaria os pacientes são novamente banhados (sabão neutro) com especial atenção à cabeça e no local da incisão cirúrgica cerca de duas horas antes da cirurgia [14]. 
Assim, a visita pré-operatória contribui para a diminuição da ansiedade, tanto do paciente como da família, possibilitando ao enfermeiro a oportunidade de orientação sobre o processo anestésico-cirúrgico e período pós-operatório, além de subsidiar a continuidade da assistência de enfermagem nos períodos intra e pós-operatório [7].

Trata-se, portanto, de um momento antes da cirurgia que influencia nas demais fases do processo. Logo deve ser visto como ferramenta que influencia no processo de saúde do cliente cardíaco, não podendo jamais ser negligenciada pelo enfermeiro, sendo esta vista como atribuiçáo do mesmo.

\section{Influência da visita de enfermagem no pós- -operatório imediato}

O processo cirúrgico é um período delicado para o paciente, pois qualquer problema nessa fase altera o bem estar físico, mental e emocional. Quando ocorre uma infecção no sítio cirúrgico, isso ocasiona um momento de estresse para o paciente e até mesmo depressão e desconforto; são momentos dolorosos até chegar o processo cicatricial, pois pode ocasionar deformidade local. Por isso, é fundamental o cuidado com a pele do paciente.

Apesar dos grandes avanços em todas as áreas da cirurgia, o controle da infecção continua sendo um grande desafio para a cirurgia. A infecção em cirurgia é uma entidade clínica de múltiplos fatores envolvidos, e a necessidade de reduzir e controlar sua incidência determina a aplicação de medidas preventivas, educacionais e de controle epidemiológico que visam, através de um processo de conscientização coletiva, levar a taxas de infecção para limites aceitáveis para o tipo de clientela e de procedimentos realizados em cada hospital [14].

O enfermeiro tem que valorizar açôes preventivas como forma de subsidiar a promoção e proteção, para que haja mudanças no método de trabalho, cuidando do paciente como um todo, verificando sua higiene, integridade da pele, seus conhecimentos em relação ao curativo cirúrgico. É essencial que o enfermeiro analise os exames pré-operatórios, focalizando o antibiograma para que se inicie uma profilaxia correta. Deve-se também verificar e analisar os materiais que serão utilizados nas cirurgias.

O paciente cirúrgico pode apresentar várias complicaçóes no pós-operatório imediato, como hipertensão, hipotensão, hipotermia, problemas circulatórios, respiratórios, hemorragias entre outros.
O enfermeiro deve ter um olhar crítico nos casos de hipotensão, pois esta também pode estar associada à presença de hemorragia, e a um sangramento atípico no local cirúrgico [16].

Na visita pré-operatória, o enfermeiro tem que atentar para o diagnóstico precoce de problemas, o que é fundamental para a recuperação de paciente submetido à cirurgia. É importante que o enfermeiro contribua para práticas de enfermagem seguras através de uma participação ativa no diagnóstico e no reconhecimento dos fatores de risco e sinais clínicos da infecção através de um plano assistencial de enfermagem voltado ao atendimento de pacientes submetidos à cirurgia, como uma relevante medida para a prevenção e controle, para assim agilizar o tratamento, estabelecendo as condutas pertinentes ao caso.

A investigação da necessidade de oxigenação e respiração no período pré-operatório visa também identificar problemas respiratórios preexistentes, que podem acarretar ou agravar complicaçóes no intra e pós-operatório [16].

A pele atua na proteçáo do corpo contra estímulos lesivos que podem ser físicos, químicos, elétricos, térmicos ou biológicos. Quando intacta, a pele bloqueia organismos patogênicos não permitindo sua entrada no corpo e ao mesmo tempo a perda ativa de água, eletrólitos e proteínas para o meio externo. A incisão cirúrgica tem como consequência a ruptura da barreira entre o meio interno e externo, daí a importância de se manter sempre limpas as feridas cirúrgicas [16].

O enfermeiro, nesta ótica, deve avaliar as feridas em questáo, determinando, sobre todas as açóes preventivas, como a correta antissepsia da pele, bem como as coberturas mais adequadas a cada tipo de incisão cirúrgica realizada. Este tipo de julgamento requer conhecimento teórico importante sobre materiais, novos estudos e atualização acerca da melhor técnica de curativo a ser empregada.

Autores verificaram que a tricotomia pode modificar a microbiota do campo operatório. Há um aumento do índice de infecção de ferida quando a tricotomia é realizada com mais de 24 horas [14].

Devido a algumas cirurgias prolongadas e ao posicionamento do paciente na sala de cirurgia, podem ocorrer processos lesivos a sua pele, úlceras por pressão e outros eventos agressivos estáo presentes no ambiente cirúrgico passíveis de atingir o paciente, como as lesóes de pele frente aos agentes químicos e queimaduras elétricas [17]. 
O enfermeiro determina a capacidade do paciente para realizar o autocuidado e proporciona o cuidado higiênico conforme as necessidades e preferência do paciente. $\mathrm{O}$ enfermeiro deve também considerar as limitaçôes físicas específicas do paciente, suas crenças, valores e hábitos. $\mathrm{O}$ enfermeiro deve utilizar todos os sentidos para a cura da mente, avaliar as respostas do paciente frente a sua condição de saúde no pós-operatório imediato [16]. Todos os pacientes apresentam algum tipo de reaçáo emocional antes de qualquer procedimento cirúrgico, seja ela evidente ou oculta, normal ou anormal. Por exemplo, a ansiedade pré-operatória pode ser uma resposta antecipada a uma experiência que o paciente visualiza como uma ameaça a seu papel habitual na vida, integridade corporal ou à própria vida. $\mathrm{O}$ sofrimento psicológico influencia diretamente o funcionamento corporal [9].

$\mathrm{Na}$ visita pré-operatória, ao obter uma história de saúde cuidadosa, a enfermeira traz à tona as preocupaçóes do paciente que podem ter um impacto no curso da experiência cirúrgica [9].

A sistematização da assistência de enfermagem perioperatória (SAEP) é um tema relevante na enfermagem, apesar da escassez de estudos na literatura nacional. A implantação de um método para sistematizar a assistência de enfermagem deve ter como premissa um processo individualizado, holístico, planejado, contínuo, documentado e avaliado. Esse método deve facilitar a prestação da assistência ao paciente como ser único, com sentimentos e necessidades únicas, com a sua anestesia e sua cirurgia, permitindo uma participação ativa e tendo como objetivo principal a visáo global do ser humano. No pós-operatório a continuidade da assistência iniciada com a visita de enfermagem deve ser obtida pelo planejamento e implementaçáo da assistência no período trans-operatório, compreendendo a avaliação pré-operatória, trans-operatória, e a pós-operatória de enfermagem [17].

Por todas as possíveis complicaçóes a que está submetido o paciente de cirurgia cardíaca compreendemos que a educação do paciente é um componente vital do processo cirúrgico. A orientação pré-operatória do paciente pode ser oferecida por meio de conversas, discussáo, uso de material audiovisual, demonstraçóes e feedback do paciente para confirmar seu entendimento. Ela é elaborada para ajudar o paciente a compreender o processo cirúrgico, para minimizar a ansiedade e promover a recuperação completa da cirurgia e anestesia [11].
O ensino do paciente tem se tornado um dos papéis mais importantes para os enfermeiros que trabalham em qualquer setor de cuidado de saúde. Os pacientes e suas famílias têm o direito à educação tanto quanto sáo capazes e de tomar decisóes instruídas e inteligentes sobre a sua saúde e estilo de vida [16].

A assistência baseada em conhecimento científico é essencial para garantir uma assistência de enfermagem de melhor qualidade, repercutindo, assim, na recuperação do cliente na prevenção de complicaçóes, na redução de tempo de internação e de gastos hospitalares, bem como no reconhecimento do profissional enfermeiro [8].

Não só o saber científico, mas também o respeito às singularidades do cliente em questáo, deve ser observado. Comprova-se que quando o mesmo sente-se mais seguro para a realizaçáo do procedimento, acaba por ter um pós-operatório mais satisfatório, o que demonstra que o indivíduo deve ser observado em sua totalidade no momento da visita pré-operatória.

Assim a assistência prestada, na visita pré-operatória, envolve aspectos de ordem técnica, científica, psicológica e também social. $\mathrm{O}$ novo padrão dos serviços de saúde é mais exigente e percebe-se que o enfermeiro deva estar mais capacitado para a realização do momento acima mencionado.

\section{Conclusão}

O enfermeiro é o profissional responsável pela visita pré-operatória e pela observação de uma série de aspectos relativos ao momento cirúrgico. Quando se pensa na cirurgia cardíaca, deve-se ter cautela absoluta, uma vez que se trata de um procedimento delicado que deve envolver uma grande integração de toda a equipe de saúde.

O profissional em questáo deve possuir um conhecimento científico adequado sobre todas as fases deste processo, sabendo correlacionar a importância da visita em questáo para o transoperatório e também para o pós-operatório de seus clientes. Trata-se de um sistema, no qual uma fase bem conduzida influi em todas as demais fases. O inverso, dentro desta questáo, também pode ocorrer, influindo de maneira negativa no estado de saúde do cliente.

Deve-se também preconizar uma assistência mais humanizada e integralizada no momento da visita pré-operatória. Entender o indivíduo náo apenas como um ser biológico se faz essencial para 
o enfrentamento desta questáo, o que se constitui como uma difícil tarefa a ser enfrentada pela equipe de enfermagem.

O enfermeiro assume papel importante quando reconhece práticas e açóes pertinentes a sua profissão. Desse modo é imprescindível que o mesmo saiba conduzir o momento da visita pré-operatória da maneira mais eficaz possível.

\section{Referências}

1. Figueiredo NMA, Viana DL, Machado WCA. Tratado prático de enfermagem. $2^{\text {a }}$. ed. Rio de Janeiro: Yendis; 2009.

2. Possari JF. Centro cirúrgico-planejamento, organização e gestão. 2a ed. São Paulo: Érica; 2006.

3. Smeltzer SC, Bare BG. Tratado de enfermagem médico-cirúrgica. 9a ed. Rio de Janeiro: Guanabara Koogan; 2002.

4. Potter PA. Potter Perry - Fundamentos de enfermagem. 5a ed. Rio de Janeiro: Elsevier; 2006.

5. Demo P. Educar pela pesquisa. Campinas: Autores Associados; 1997.

6. Roman AR, Friedlander MR. Revisão integrativa de pesquisa aplicada à enfermagem. Cogitare Enferm 1998;3(2):109-12.

7. Fonseca RMP, Paniche ACG. Enfermagem em centro cirúrgico: Trinta anos após criação do sistema de assistência de enfermagem perioperatória. Acta Paul Enferm 2009;22:112-16.

8. Neto AP, Teixeira JBA, Barbosa MH. Elaboração de um instrumento para o preparo pré-operatório em cirurgias cardíacas. O Mundo da Saúde 2008;32(1):107-10.

9. Smeltzer SC, Bare BG. Brunner e Suddarth: Tratado de enfermagem médico-cirúrgica. 10a ed. Rio de Janeiro: Guanabara Koogan; 2005.

10. Leite JL, Figueiredo NMA, Erdmann AL. Guia prático em cardiopatias: Enfermagem em cirurgias cardíaca. 1a ed. Rio de Janeiro: Yendis; 2006.

11. Nettina SM. Brunner: Prática de enfermagem. $8^{\text {a }}$ ed. São Paulo: Guanabara Koogan; 2005.

12. Grittem L, Méier MJ, Gaievicz AP. Visita pré-operatória de enfermagem: Percepçóes dos enfermeiros de um hospital de ensino. Cogitare Enferm 2006;11:245-51.

13. Moraes LO, Peniche ACG. Assistência de enfermagem no período de recuperação anestésica: Revisão literária. Rev Esc Enferm USP 2003;37:32-45.

14. Ferraz EM, Ferraz AAB, Bacelar TS, D’Albuquerque ESTD, Vasconcelos MDMM, Leão CS. Controle de infecção em cirurgia geral-resultado em um estudo prospectivo de 23 anos e 42.274 cirurgias. Rev Col Bras Cir 2001;28:100-8.

15. Darli CC. Diagnósticos de enfermagem de pacientes em período pós-operatório imediato de cirurgia colicistectomia laparoscópica [dissertaçáo]. Ribeirão Preto: Universidade de SP; Escola de Enfermagem de Ribeirão Preto; 2005;

16. Ursi ES, Gavão CM. Prevenção de lesão de pele perioperatório: Revisão integrativa da literatura. Rev Latinoam Enferm 2006;14:32-38.

17. Picolli $\mathrm{M}$, Galvão $\mathrm{CM}$. Enfermagem perioperatória: identificação do diagnóstico de enfermagem, risco para infecção fundamentada no modelo conceitual de Levine. Revista Latinoam Enferm 2001;4:234-42. 